\title{
DEEPWATER SEMISUBMERSIBLE MOTION SIMULATION
}

\author{
David R. Shields, Robert F. Zueck \\ Ocean Structures Division \\ Naval Civil Engineering Laboratory \\ Port Hueneme, California 93043
}

\begin{abstract}
Moored semisubmersible buoys are proposed as ocean facilities for Navy ranges. In deep water (depths near 6,000 feet), these small, moored platform systems have large scale nonlinear motions which are neither platform dominated nor mooring dominated. Techniques are available to simulate the motions of both large semisubmersibles and small oceanographic buoys. Techniques are not available to simulate the complex motion of mediumsize, deep water ocean platform systems. This paper presents details about activities at NCEL for developing technology for small deepwater semisubmersible motion simulation. Specific activities include developing a numerical simulation package, performing an at-sea motion measurement experiment for validation data, and conducting various related studies.
\end{abstract}

\section{Background}

Moored floating ocean platforms are in two principal class sizes: large shallow water and small deep water, as indicated in Figure 1. The principal uses of the large platforms have been for

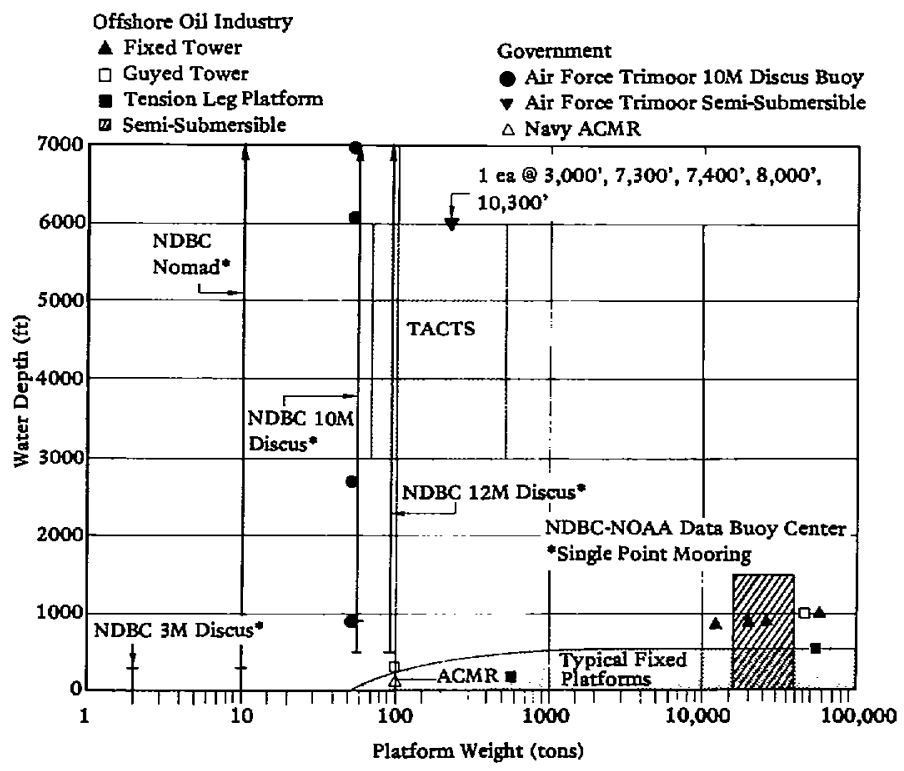

Figure 1. Long-term ocean platforms. construction purposes and offshore mineral exploration and exploitation. The small platforms are primarily used by the oceanographic community. The requirements by both groups are unique. The oceanographic community has requirements that allow for small buoys with low payload capabilities and large motions. The oceanographic buoy may be characterized as a wave follower; i.e., its motions follow the surface wave in amplitude and slope.

Large platforms are used where high payloads and small motions are required. The offshore construction and petroleum industry are the principal users of these platforms. These platforms are ship-shape vessels, construction barges or semisubmersibles which are used for drilling, production, and construction. A recent platform concept, the tension leg platform (TLP), has a hull configuration similar to the semisubmersible but uses a vertically tensioned mooring. The semisubmersible has become the industry standard when a high stability, low motion platform is required.

The semisubmersible was designed and developed primarily by the offshore petroleum industry beginning in the late 1950 s as an exploratory drilling vessel whose displacements range from 13,000 to 33,000 short tons. During the 1970s, semisubmersible hull use was extended by the offshore petroleum industry to include floating production facilities, construction and diving support platforms, pipelaying vessels, dredges and accommodation platforms. In each case, the semisubmersible has replaced barge or ship-shape vessels for these tasks to provide reduced motions (reduction of two to four times) resulting in much longer working periods since operations may continue in higher sea states. The semisubmersible hull has been proposed for use as a mobile radar tracking ocean platform for NASA, the U.S.A.F. and the Navy.

Deep water moored ocean platforms have been proposed for supporting offshore air combat training systems. These of fshore ranges will consist of an array of four or more ocean platforms, each with electronic tracking equipment for training exercises. The requirements for the platforms are unique in that both small deck payload capacity and small platform motions are required. For applications such as this, References 5,10 , and 15 have arrived at the conclusion that the semisubmersible hull form offers the greatest stability when compared to the other common buoy hull forms; e.g., discus, boat-shaped, and spar. 
The semisubmersible size identified for Navy applications is much smaller than that used by the offshore industry. The displacement differs by 2 orders of magnitude with Navy platforms requiring displacements of less than 1,000 short tons. These small platforms should be called semisubmersible buoys to distinguish them from their larger relatives (Figure 2 provides a dramatic size comparison). The hulls of these semisubmersible buoys can be characterized by a space frame assembly of slender members (hydrodynamically speaking) with overall platform displacements in the range of 200 to 1,000 short tons. Depending on depth and other factors, the semisubmersible buoy may utilize catenary or taut mooring configurations with elements of chain, wire rope, and/or synthetic ropes.

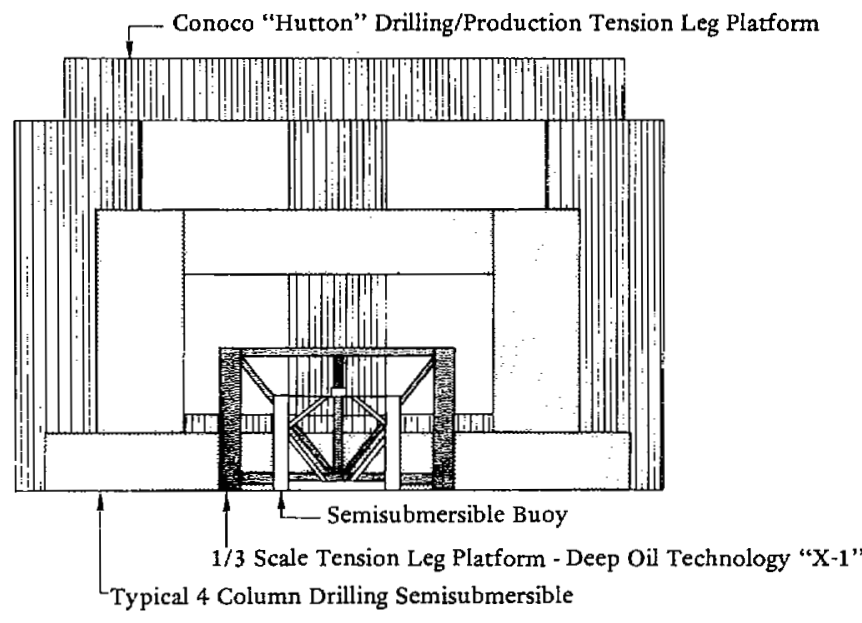

Figure 2. Comparison of hull sizes of platforms.

The semisubmersible buoy was found to have superior angular response (pitch/roll) and heave response amplitude operators with the best characteristics within the wave frequency range (Ref 15). The basic advantage of the semisubmersible hull forms lies in its ability to decouple the water plane inertia from the water plane area while keeping both independent from displacement (Ref 5). Then the pitch (or roll) periods which depend on the water plane inertia can be controlled separately from the heave periods which are dependent on water plane area and displacement. The fact that the semisubmersible configuration is "transparent" to the waves also improves its motion stability characteristics. The result is a platform which maintains motion within a set of defined limits for a higher percent of the time than most other hull forms. This taken with the versatility of the semisubmersible and the fact that it is not "finely tuned" to a narrow band of sea spectra frequencies but remains effective over a broad band of frequencies makes the semisubmersible a very effective hull form.

Figure 3 presents various semisubmersible buoys which have been either proposed or built. Platform A was selected as the best buoy for use as an offshore AWACS reflector platform (Ref 5 ). Platform B, described in Reference 10, has been selected for use by the U.S.A.F. and similar configurations are being investigated by NCEL. Platform $\mathrm{C}$ is presently being investigated as a possible Navy configuration. Platform $D$ has been used for a one-third scale ocean test of the TLP concept (Ref 7 ), and also used with a catenary mooring for OTEC cold-water pipe studies (Ref 2 and 9).
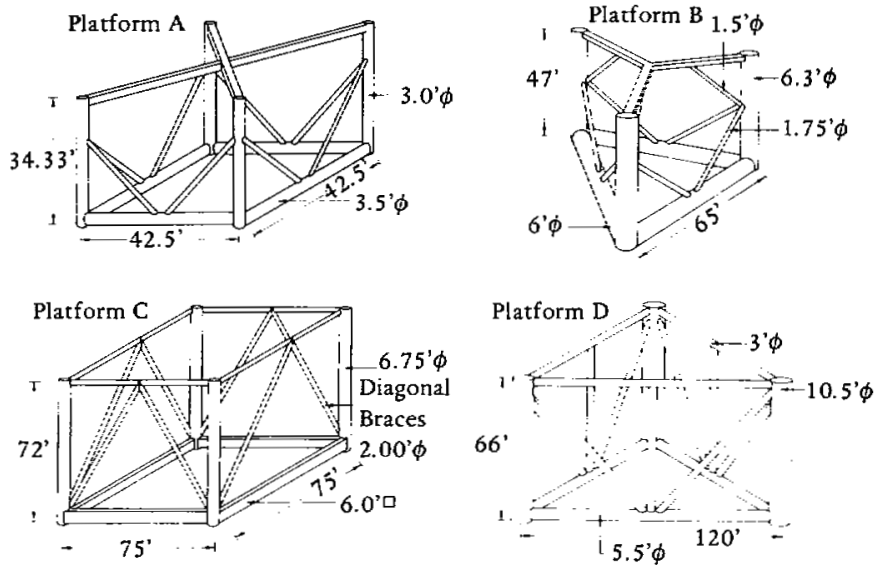

Figure 3. Semisubmersible buoy hulls, either proposed or built.

\section{Platform Motion Simulation}

Techniques for modeling floating objects subject to wave excitation differ according to the type of platform being modeled as shown in Figure 4. The hydrodynamic modeling of slendermember space-frame floating platforms is based on a relative motion formulation of the Morison equation. This formulation includes terms for the inertia, drag, and Froude-Krylov forces due to the combined effect of platrorm motion, currents, and waves (Ref 12). The inertia and drag forces are computed using relative accelerations and velocities, respectively. The hydrodynamic forces are computed separately for each member and then assembled with appropriate transformations into six-degree-of-freedom equations of motion for the floating platform as a whole.

Techniques for modeling the mooring system range from simple linear springs to complex super finite elements as shown in Figure 5. Present techniques for simulating the motions of large semisubmersibles use either linear springs, nonlinear springs or catenary equation representations of the mooring legs. Neither of these mooring models represent the hydrodynamic loading due to current on the mooring legs, as this is not usually required for large semisubmersibles moored in shallow water. For small semisubmersible buoys, the hydrodynamic loading due to current on the mooring legs becomes equal to or greater than the hydrodynamic force on the floating platform alone. In this case, current modified catenary equations or finite elements must be used to model the mooring legs. Finite element methods also include an option to model the full dynamics of the mooring legs. The super finite element model provides a convenient technique for representing the mooring legs as a simple six-degree-of-freedom model with all the benefits of a full finite element model. 


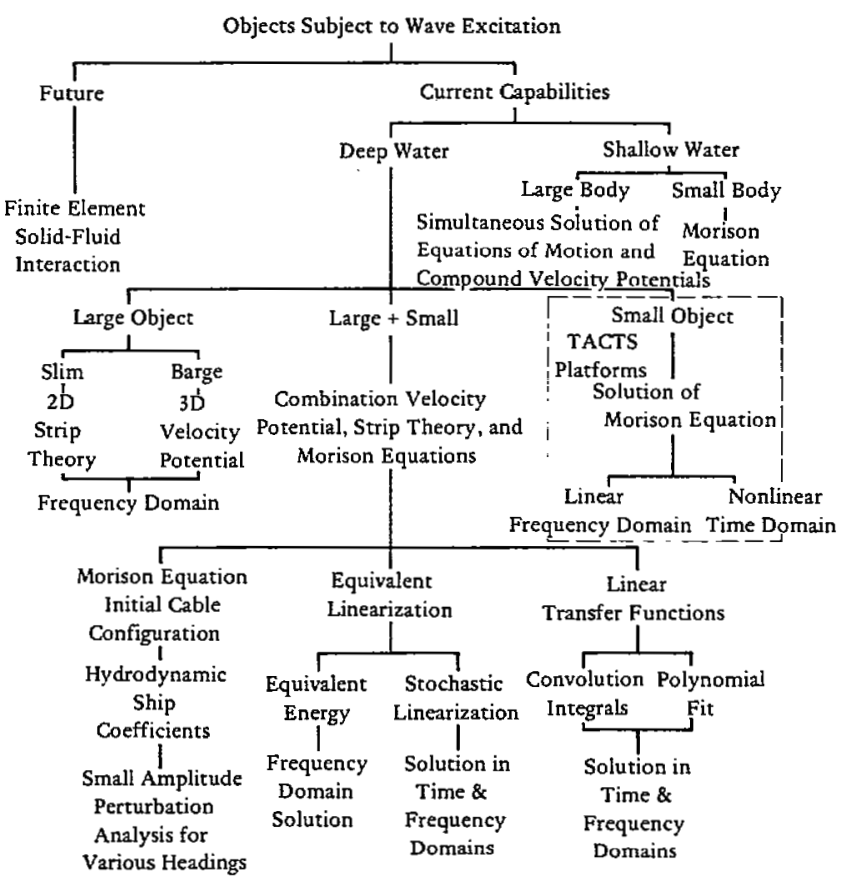

Figure 4. Overview of simulation techniques for floating objects (Adapted from Ref. 13.).

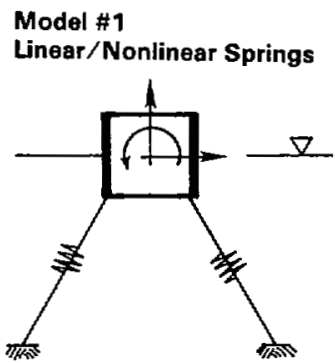

Model \#3

Linear Mat./Current Modified Catenary EON.

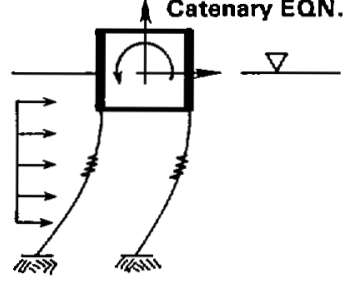

Model \#2

Linear Mat./Catenary EQN.

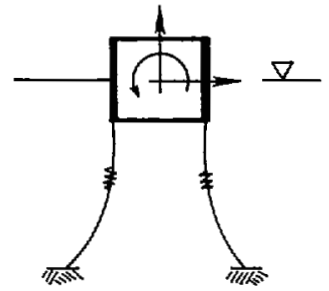

Modal \#4

Finite Element w/Dynamics

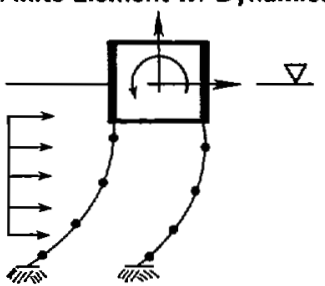

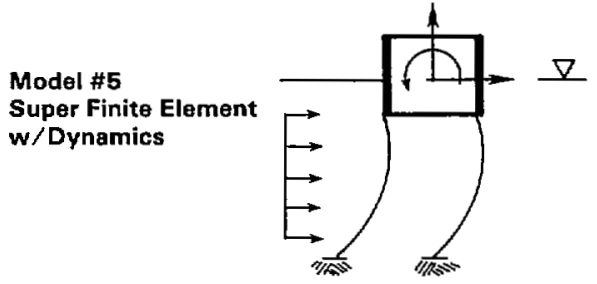

Figure 5. Mooring models for deepwater platform systems.
Techniques for simulating response of small deep water platforms using finite element modeling of the mooring legs are not presently available. This simulation requires the coupling of a slendermember space-frame floating platform program with a finite element mooring cable dynamics program. NCEL has developed a large number of simulation techniques for cable dynamics including the SEADYN computer program. The SEADYN numerical analysis model simulates the nonlinear, threedimensional displacement responses of cable systems in the ocean environment. It is based on a finite element representation and has features for bottom interactions, wind and wave forces, spatial and time-variant currents, point loads, material nonlinearities and fluid effects (Ref 16). A variety of subanalyses are available in SEADYN to apply loads and calculate responses including nonlinear static, nonlinear dynamic (time domain) and linearized dynamic (frequency domain) analyses. SEADYN presently has limited ability to model slender-member space-frame platforms.

Using SEADYN in its present form, several static analyses were performed on the deepwater semisubmersible buoy system outlined in Figure 6 . Each mooring leg is represented by 17 finite elements. The floating platform is modeled as a six-degree-of-freedom rigid body with connections to each mooring leg.

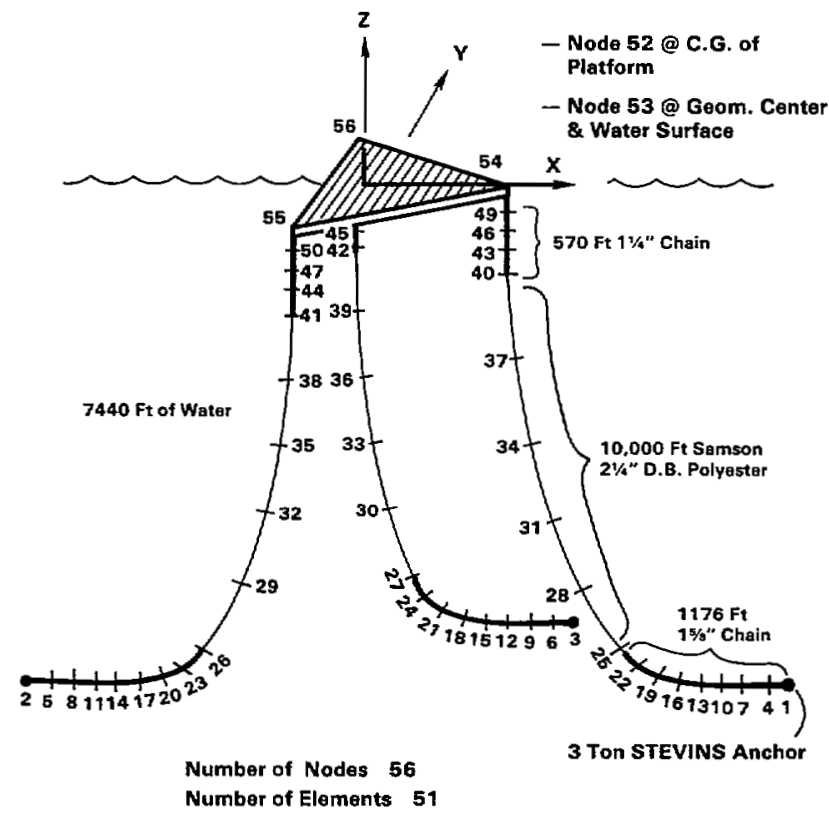

Figure 6. A representative deepwater semisubmersible buoy model.

In a representative simulation, the semisubmersible buoy system model was subjected to static current, wind and surface drift forces as shown in Figure 7. Under these conditions the maximum static deflection was 1,610 feet in 7,440 feet of water. The simulation is significant in its portrayal of the large displacements produced by hydrodynamic loading due to current on the mooring legs. These large displacements mandate the use of finite element modeling rather than the usual linear spring modeling of the mooring legs. 


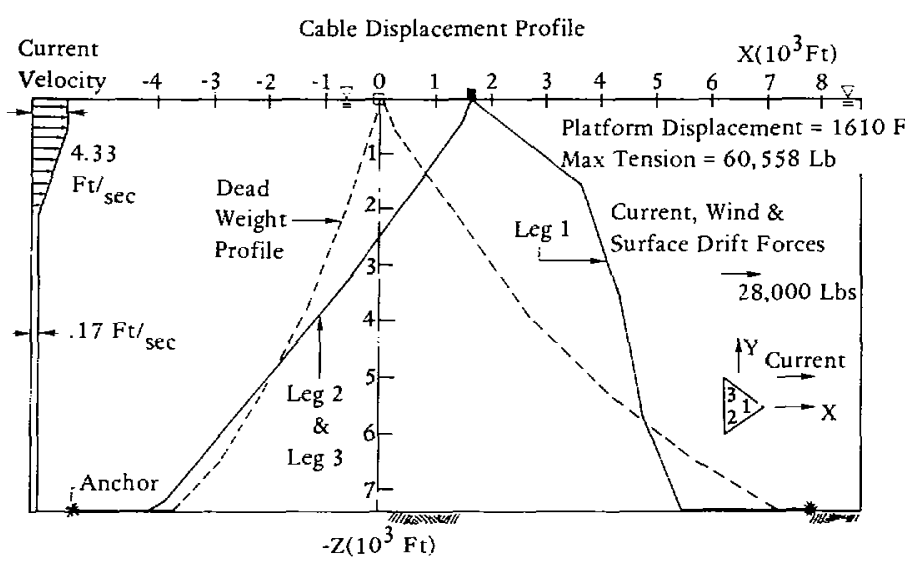

Figure 7. Static simulation results for the semisubmersible buoy model.

With finite element modeling, the hydrodynamic loading due to current on the mooring legs can be correctly represented.

Appropriate linearized frequency and nonlinear time domain motion analysis programs will be incorporated with the SEADYN finite element cable dynamics program. This will provide a unique computer analysis package for simulation of the coupled motion of moored semisubmersible buoys due to current, wind, and wave. Using this analysis package, the dynamic response can be simulated of various semisubmersible buoys with different hull designs, mooring configurations, mooring materials, and force coefficients to determine the effect of these parameters on the various designs.

\section{Platform Motion Simulation Validation}

When complex numerical simulation models such as these are developed a comprehensive validation of the computer program is required to assess the accuracy of its simulation techniques. To acquire validation data a representative experiment is usually conducted. For ocean engineering problems, in general, a prototype scale or largescale model experiment is most desirable because of the lack of effects introduced by scale ratios. At small-scale ratios hydrodynamic conditions cannot be correctly simulated because of the extremely low Reynolds numbers produced. Typical large-scale experiments for purposes such as this are described in References 3 and 7.

For the previous reasons and to acquire a data base in the performance of semisubmersible buoys, a motion measurement experiment (MIME) will be conducted. The MME will utilize a largescale model of a generic range platform moored in a representative water depth off the coast of California. Meteorologic, oceanographic, platform motion, mooring tension and platform position data will be collected during the MIME. The experiment will be conducted over an appropriate period of time to obtain environmental and platform response data which will be representative of survival, operational, and fatigue sea states. Figure 8 illustrates the MME site with the key elements of the experiment. Meteorological, oceanographical, and motion sensors on the platform, similar to those described in References 1, 4, and 9, will collect digital data which is transmitted to shore, recorded and checked to see that sensors are functioning properly and that the quality of data required is obtained. The environmental data collected in the experiment will be used as input to the numerical simulation models. The data will be processed so that comparisons can be made between the response output of both the frequency and time domain numerical simulation models with the platform response data from the MME. These comparisons will be used to determine the accuracy of the numerical simulation models.

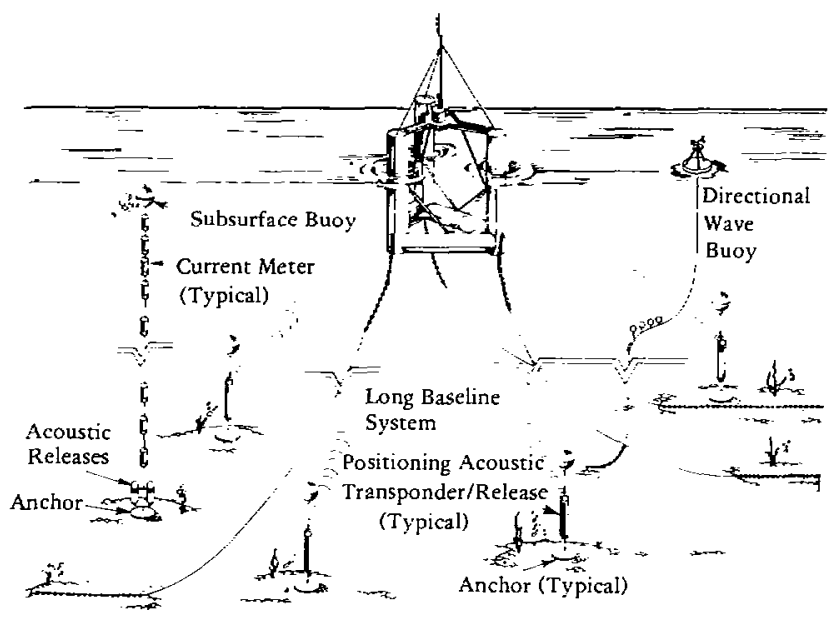

Figure 8. Key elements of motion measurement experiment.

\section{Other Related Activities}

Other activities included within the overall Offshore Range Facilities Development Plan (Ref 13) include: (1) platform hydrodynamics, (2) platform reliability, (3) mooring components, and (4) fiber optic technology.

Hydrodynamic forces on these platforms are computed using the relative motion formulation of the Morison equation. Although extensive experimental work has been conducted to determine the drag and inertia coefficients for stationary vertical cylinders in both periodic and random waves, little attention has been given to the problems of force coefficients for cylinders undergoing large displacements (References 8 and 11). A two-phase experimental program to determine the importance of relative motion on the force coefficients is presently being developed. Reference 6 identified four research areas related to cable dynamics: (1) hydrodynamic drag on long deep water mooring cables, (2) shear flow effects, (3) slack cable dynamics, and (4) non-resonant cable strumming. The first of these topics will be investigated to characterize the hydrodynamic drag on long deep water mooring cables. The other topics are receiving investigaton in other programs. 
Risk assessment of offshore structures is important because it allows the uncertainties and design options to be considered in a rational manner, a consistent set of safety factors to be established, and critical design or environmental conditions to be identified. Quantitative values for risk may only be obtained through formalized structural reliability analyses. NCEL has proposed the development of a reliability based approach for the design of deepwater range platforms.

Synthetic ropes are emerging as the deep water mooring element of the future. Reference 14 identified three major technology deficiencies for deep water mooring elements: (1) little or no S-N data on medium to large polyester and Kevlar ropes, (2) no validated fatigue prediction model for synthetic ropes, and (3) little or no information on the performance of various terminations for medium to large polyester and Kevlar ropes. Formulation of investigations which will address these technology deficiencies is being pursued.

The feasibility of using fiber optic cables for platform-to-platform and platform-to-shore data transmission links is also being investigated for these electronic systems.

Most of the activities are already underway at NCEL to provide the technology necessary to design and construct semisubmersible buoys and their moorings for the Navy's deep water mooring facilities. The results of this effort will provide necessary knowledge to designers of semisubmersible buoys and their associated deep water moorings.

\section{Acknowledgments}

The authors are grateful to the Naval Facilities Engineering Command for their sponsorship of this work.

\section{References}

1. J.H. Brewer, S.J. Chou, and C. Tucker. "Instrumentation for tension leg platform environmental tests," Ocean Engineering, Undated.

2. H.L. Donnelly, J.T. Stadter, R.O. Weiss, and L. Perez y Perez. "Cold water pipe verification test," in Proceedings of the 6th Ocean Thermal Energy Conversion Conference, Washington, D.C., Jun 1979.

3. L.D. Finn and K.E. Young. "Field test of a guyed tower," in Proceedings of the Offshore Technology Conference, OTC 3131, Houston, Tex., May 1978.

4. G.Z. Forristall, J.R. Kreider, and A.M. Reece. "Semisubmersible rig motion studies offshore of Alaska and southern California," in Proceedings of the Offshore Technology Conference, OTC 3557, Houston, Tex., May 1979.

5. W.H. Garzke, Jr., G.L. Petri, A.C. McClure, C. Fink, and J. Giannotti. Design of a reflector buoy for AWACS radar: engineering report on design and computer analysis, NOAA Data Buoy Office. NSTL Station, Miss., Jul 1978.
6. O.M. Griffin. "Marine cable strumming and its prevention," NCEL Ocean Platform Seminar, by D.R. Shields, Naval Civil Engineering Laboratory, Technical Note N-1681. Port Hueneme, Calif., Nov 1983.

7. E. Horton. "Tension leg platform prototype completes Pacific Coast test," Ocean Industry, Sep 1975 .

8. R.T. Hudspeth. "Environmental forces on ocean platforms," NCEL Ocean Platforms Seminar, by D.R. Shields, Naval Civil Engineering Laboratory, Technical Note N-1681. Port Hueneme, Calif., Nov 1983.

9. John Hopkins University, Applied Physics Laboratory. Verification test for cold water pipe analysis, Part A: Test description, results and model comparisons, JHU/APL SR 80-2A. Oct 1980.

10. A.C. McClure and I.N. Kirchner. "Semisubmersible buoy for stormy seas," in Proceedings of the 1983 symposium on buoy technology, Marine Technology Society, New Orleans, La., Apr 1983.

11. J.H. Nath. "Feasibility report on experimental determinations of force coefficients for relative motion Morison equation," Naval Civil Engineering Laboratory. Port Hueneme, Calif., Aug 1983. (unpublished manuscript)

12. J.R. Paulling. Survey of methods and research needs for dynamic analysis of sensor platforms, Naval Civil Engineering Laboratory. Port Hueneme, Calif., Aug 1980. (unpublished manuscript)

13. D.R. Shields. Offshore air combat training facilities technology development plan, Naval Civil Engineering Laboratory, Technical Memorandum TM-44-83-10. Port Hueneme, Calif., Sep 1983.

14. D.R. Shields and R.L. Wendt. "Synthetic rope mooring elements for long-term sensor platforms: a working paper," Naval Civil Engineering Laboratory, Port Hueneme, Calif., Jul 1983. (unpublished manuscript)

15. D.R. Shields, A.T. Maris, and L.A. Vega. "Long term sensor platform," in Proceedings of the 1983 Symposium on Buoy Technology, Marine Technology Society, New Orleans, La., Apr 1983.

16. R.L. Webster and P.A. Palo. SEADYN user's manual, Naval Civil Engineering Laboratory, Technical Note N-1630. Port Hueneme, Calif., Apr 1982 . 